tion by a Tubbs dilator was assessed on the operating table by palpation of the valve as is routinely done. The maximum dilatation of the balloon was done according to the height of the patient, as specified. The adequacy of release of the mitral valve was assessed by finger palpation of the mitral valve apparatus and by simultaneous pressure recordings of the left atrium and the left ventricle. The end-diastolic gradient across the mitral valve was calculated from recordings of mean left atrial pressure (LAP) and left ventricular end-diastolic pressure (LVEDP).

The results are summarized in Table III and IV. The data were subjected to paired $t$ test. There was no significant difference between the two groups with reference to predilatation LVEDP, LAP, or the predilatation gradient (LAP-LVEDP). Hence we compared the residual gradient after Tubbs dilatation (group II) and balloon dilatation (group I). The residual gradient after Tubbs dilatation (group II) was significantly higher than that after balloon dilatation (group I). It also follows that balloon dilatation after Tubbs dilatation (group II) significantly reduced the residual gradient, whereas Tubbs dilatation after balloon dilatation (group I) did not significantly reduce the gradient. Representative pressure tracings from the two groups are shown in Figs. 1 and 2.

On finger palpation, the mitral valve apparatus was extremely well opened after balloon dilatation in terms of commissural and subvalvular release (group I). Subsequent Tubbs dilatation did not improve the results. The commissural and subvalvular release were also thought to be better after the subsequent balloon dilatation (group II). However, this is a subjective evaluation.

This study has led us to believe that the balloon with its circumferential dilatation and radial stretching capabilities might be a better valve dilator. On the basis of this hypothesis we have been trying to manufacture a transventricular balloon dilator. The work is still in its infancy but initial trials have encouraged us to move forward. We hope to publish more data in the future.

We acknowledge the assistance of David C. Naftel, $\mathrm{PhD}$, Department of Surgery, Division of Cardiothoracic Surgery, University of Alabama, Birmingham.

\section{REFERENCES}

1. Inoue $\mathrm{K}$, Owaki $\mathrm{T}$, Kitamura $\mathrm{F}$, et al. Clinical application of transvenous mitral commissurotomy by a new balloon catheter. J Thorac CARdIOvasc SuRg 1984;87: 394-402.

2. Al Zaibag M, Ribeiro PA, Alkasab S, et al. Percutaneous double balloon vavulotomy for rheumatic mitral stenosis. Lancet 1986;1:757-61.

3. Palacios I, Block PC, Brandi S, et al. Percutaneous balloon valvotomy for patients with severe mitral stenosis. Circulation 1987;75:778-84.

4. Wilkins GT, Weyman AE, Abascal VM. Percutaneous balloon dilatation of the mitral valve: an analysis of echocardiographic variables to outcome and the mechanism of dilatation. Br Heart J 1988;60:299-308.

5. Lock JE, Khalillulah M, Shrivastava S, Bahl V. Percutaneous catheter commissurotomy in rheumatic mitral stenosis. N Engl J Med 1985;313:1515-8.

6. Patel J, Shama D, Mitha AS, et al. Balloon valvuloplasty versus closed commissurotomy for pliable mitral stenosis: a prospective hemodynamic study. J Am Coll Cardiol 1991;18:1318-22.

7. Turi ZG, Reyes VP, Somraju B, et al. Percutaneous balloon versus surgical closed commissurotomy for mitral stenosis: a prospective randomized trial. Circulation 1991;83:1179-85.

\title{
TRANSFER OF THE POSTERIOR TRICUSPID LEAFLET AND CHORDAE FOR MITRAL VALVE REPAIR
}

Ulrik Hvass, MD, ${ }^{\mathrm{a}}$ José Calliani, MD, ${ }^{\mathrm{a}}$ Isabelle Nataf, ${ }^{\mathrm{a}}$ Jean Michel Julliard, MD, ${ }^{\mathrm{b}}$ and Alex Vahanian, MD, ${ }^{\mathrm{c}}$ Paris, France

Efficient mitral valve repair is preferable to mitral valve replacement. The issue is particularly important in young female patients to avoid anticoagulants or rapid deterioration of xenografts.

From Cardiovascular Surgery ${ }^{\mathrm{a}}$ and the Department of Cardiology, ${ }^{\mathrm{b}}$ Hôpital Bichat, and the Department of Cardiology, Hôpital Tenon, Paris, France.

J Thorac Cardiovasc Surg 1995;110:859-61

Copyright $(1995$ by Mosby-Year Book, Inc.

0022-5223/95 $\$ 5.00+0 \quad \mathbf{1 2 / 8 / 6 1 6 8 6}$
The variety of techniques proposed for mitral valve repair is already impressive and responds to anatomic and functional necessities. Among others, the techniques comprise the "French correction," creation of several anuli, transfer of segments of the posterior leaflet, ${ }^{2}$ use of artificial chordae, ${ }^{3}$ valvular augmentation with the patient's own tanned pericardium, ${ }^{4}$ and use of segments of mitral cryopreserved homografts with their chordae. ${ }^{5}$

We report on a new technique that allowed us a conservative approach in a difficult case.

A 22-year-old Algerian woman had isolated rheumatic mitral stenosis. Preoperative echographic evaluation showed a calculated surface area of $0.7 \mathrm{~cm}^{2}$, a mean 
transvalvular gradient of $16 \mathrm{~mm} \mathrm{Hg}$, a trivial central leak, a mobile anterior leaflet, a retracted posterior leaflet, and a fused, thickened subvalvular apparatus.

Although not an ideal candidate, the patient was finally accepted for percutaneous mitral dilatation by Professor Vahanian of the Tenon Hospital in Paris, who has exten-

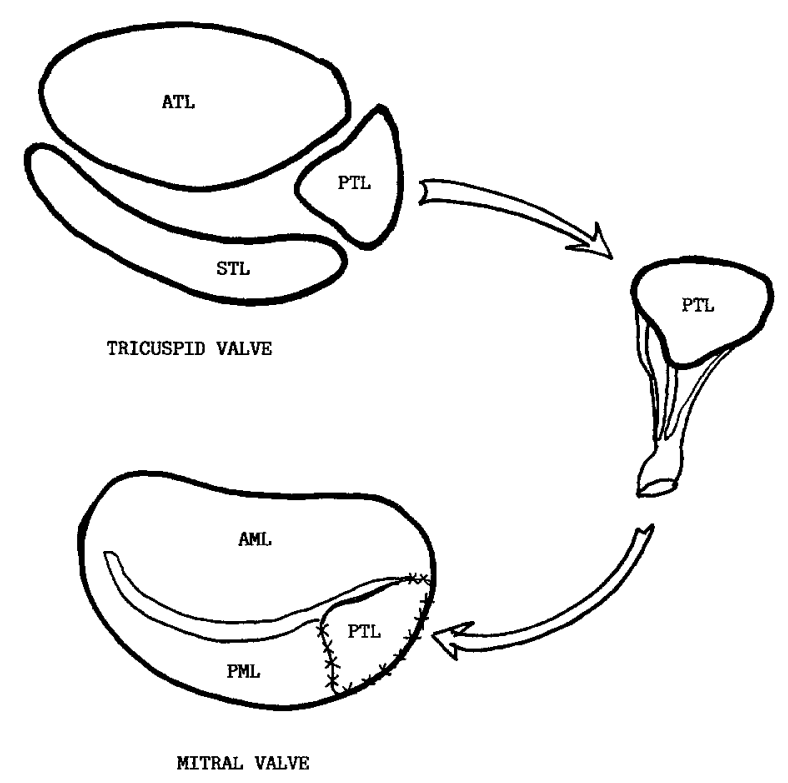

Fig. 1. Transfer of posterior tricuspid leaflet to the mitral valve. $A M L$, Anterior mitral leaflet; $A T L$, anterior tricuspid leaflet; $P M L$, posterior mitral leaflet; $P T L$, posterior tricuspid leaflet; $S T L$, septal tricuspid leaflet. sive experience in the field. The procedure resulted in a tear of the posterior leaflet, with severed chordae and grade III mitral regurgitation. Catheterization of the right side of the heart showed a capillary pressure of $26 \mathrm{~mm} \mathrm{Hg}$ and a pulmonary artery pressure of $45 / 25 \mathrm{~mm} \mathrm{Hg}$ (mean $30 \mathrm{~mm} \mathrm{Hg}$ ). The patient was scheduled for surgery 3 days later.

At operation, the mitral anulus was rather small, and the anterior leaflet was flexible. The anterior commissure had a $3 \mathrm{~mm}$ tear, which had been stopped by fused and short $(5 \mathrm{~mm})$ submitral anterior chordae. A long irregular tear was located near the posterior commissure, extending to the anulus of the posterior leaflet. Several chordae had been severed.

We proceeded as follows: The anterior commissure was opened a further 4 to $5 \mathrm{~mm}$ and a $2 \mathrm{~cm}$ split was created in the anterior papillary muscle. Direct suture of the lacerated posterior leaflet gave an unsatisfactory result, with insufficient opening and unacceptable regurgitation. The possibility of any form of repair seemed compromised, and only a small xenograft, probably $25 \mathrm{~mm}$, would have been suitable for the patient's anulus and small left ventricle. We decided to evaluate the tricuspid valve. The anulus was large and the valvular tissue normal. The posterior leaflet, its chordae, and its muscular attachment were well individualized. This portion of the tricuspid valve was removed and transferred to the mitral commissure (Fig. 1). The tricuspid papillary muscle was reattached to the corresponding mitral papillary muscle with several pledget-supported sutures. The leaflet was reattached to the mitral anulus and adjacent mitral tissue with interrupted 5-0 monofilament sutures. Injection of saline solution into the left ventricle, to test for mitral competence, showed a good result. We did not use a prosthetic

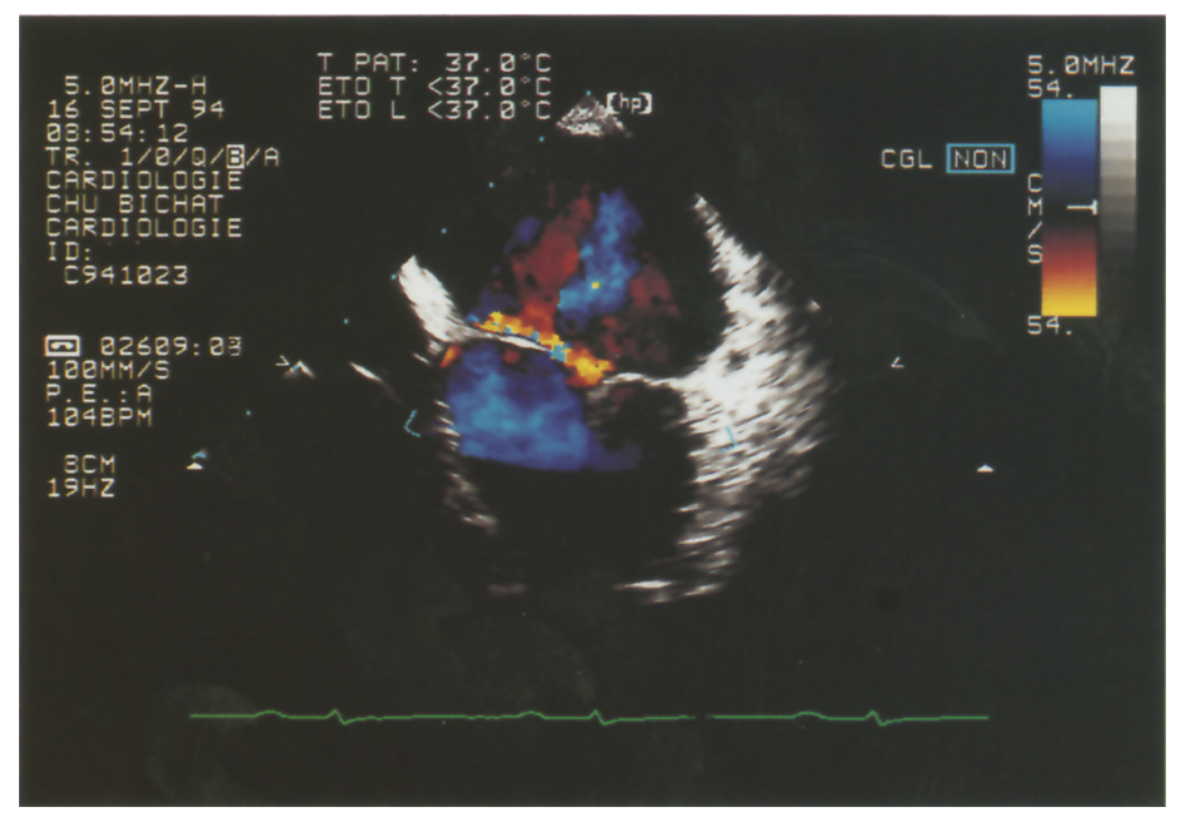

Fig. 2. Postoperative transesophageal echocardiogram shows narrow regurgitation that follows the anterior mitral leaflet. 
mitral anulus. The tricuspid valve was repaired by annular plication and leaflet suture.

The postoperative course was uneventful. A transesophageal echocardiogram 2 weeks later showed narrow mitral regurgitation located at the level of the anterior commissure and extending along the anterior leaflet (Fig. 2 ), with normal function in the area of the reconstructed posterior commissure, a mean transmitral gradient of 8 $\mathrm{mm} \mathrm{Hg}$, and a calculated surface area of $1.95 \mathrm{~cm}^{2}$. The tricuspid valve had a mild to moderate leak.

Although many questions remain unanswered with this type of repair, use of the posterior leaflet of the tricuspid valve may be helpful for mitral repair.

\section{REFERENCES}

1. Carpentier A. Cardiac valve surgery-the "French correction." J Thorac CARDIOVASC SuRg 1983;86:32337.
2. Hvass U, Pansard Y, Lamberti A, et al. Réparations de lésions mitrales rhumatismales par transfert d'un segment de la valve posterieure avec ses cordages sur la valve anterieure. Arch Mal Coeur 1986;1: 103-6.

3. David TE, Boss J, Rakowski H. Mitral valve repair by replacement of chordae tendinae with polytertrafluoroethylene sutures. J THORAC CARDIOvasc SuRg 1991;101: 495-501.

4. Pellerin M, Chauvaud S, Chachques JC, Carpentier A. Mitral leaflet extension with glutaraldehyde treated autologous pericardium. Presented at the Sixth International Symposium on Cardiac Bioprostheses. Vancouver, BC, Canada. July 29-31, 1994.

5. Acar C, Farge A, Ramsheyi A, et al. Mitral valve replacement using a cryopreserved mitral homograft. Ann Thorac Surg 1994;57:746-8.

\title{
SUCCESSFUL TREATMENT OF LIFE-THREATENING ACUTE REPERFUSION INJURY AFTER LUNG TRANSPLANTATION WITH INHALED NITRIC OXIDE
}

\author{
P. Macdonald, FRACP, PhD, J. Mundy, FRACS, P. Rogers, BSc, G. Harrison, FRANZCA, J. Branch, FRANZCA, \\ A. Glanville, FRACP, MD, A. Keogh, FRACP, MD, and P. Spratt, FRACS, FRCS(Edin), Darlinghurst, Australia
}

\footnotetext{
Acute reperfusion injury is a potentially life-threatening complication of lung transplantation. Typically, acute reperfusion injury becomes apparent within hours of completion of the transplant procedure and in its most severe form results in progressive hypoxemia, pulmonary hypertension, systemic hypotension, and diffuse opacification of the transplanted lung or lungs on chest x-ray films, a clinical syndrome known as the reimplantation response. ${ }^{1}$ The pathophysiologic disturbance and clinical picture of acute reperfusion injury closely resembles adult respiratory distress syndrome (ARDS), a condition that has been successfully treated with inhaled nitric oxide (iNO). ${ }^{2}$ In this report we describe two cases of severe acute reperfusion injury after lung transplantation that were treated with iNO. In both cases, iNO rapidly reversed the respiratory failure and associated hemodynamic abnormalities.

Case 1. A 50-year-old woman underwent left single lung transplantation because of smoking-induced emphysema on December 31, 1993. The donor was a 22-year-old woman who died after craniotomy. Arterial oxygen tension $\left(\mathrm{PaO}_{2}\right)$ to inspired oxygen fraction $\left(\mathrm{FiO}_{2}\right)$ ratio was

From the Cardiopuimonary Transplant Unit, St. Vincent's Hospital, Darlinghurst, New South Wales, Australia.

J Thorac Cardiovasc Surg 1995;110:861-3

Copyright $\odot 1995$ by Mosby-Year Book, Inc.

$0022-5223 / 95 \$ 5.00+0 \quad \mathbf{1 2 / 5 4 / 6 2 8 3 7}$
}

$388 \mathrm{~mm} \mathrm{Hg}$ before procurement. The ischemic time for the donor lung was 384 minutes. The initial postoperative $\mathrm{PaO}_{2} / \mathrm{FiO}_{2}$ ratio was $216 \mathrm{~mm} \mathrm{Hg}$. A chest x-ray film taken 1 hour after operation showed full expansion of the transplanted lung with no radiologic infiltrate. The patient was extubated at 12 hours after operation. During the next 45 minutes increasing dyspnea occurred. A repeat chest $\mathrm{x}$-ray film showed diffuse opacification of the transplanted lung. Shortly after the film was obtained the patient had cardiorespiratory arrest. She required prolonged resuscitation before a stable cardiac rhythm could be reestablished and she remained critically ill during the next 6 hours with profound hypoxemia $\left(\mathrm{PaO}_{2} / \mathrm{FiO}_{2}\right.$ ratio in the range of 70 to $80 \mathrm{~mm} \mathrm{Hg}$ ) and shock (mean systemic blood pressure between 45 and $55 \mathrm{~mm} \mathrm{Hg}$ with severe oliguria) despite intravenous infusions of high-dose adrenaline and noradrenaline. Mean pulmonary artery wedge pressure remained in the range of 10 to $14 \mathrm{~mm} \mathrm{Hg}$ but pulmonary vascular resistance (PVR) was markedly elevated (calculated mean PVR in the range of 350 to 400 dynes $\cdot \mathrm{sec} \cdot \mathrm{cm}^{-5}$ ). Administration of iNO was begun at an inspired concentration of $36 \mathrm{ppm}$. NO was added at the ventilator end of the inspiratory limb of a Servo $900 \mathrm{C}$ ventilator (Siemens, Solna, Sweden). Within the next 15 minutes $\mathrm{PaO}_{2}$ rose from 73 to $103 \mathrm{~mm} \mathrm{Hg}$ and within 1 hour this value rose to $212 \mathrm{~mm} \mathrm{Hg}$. Hemodynamic changes in response to iNO are summarized in Table I. An attempt to wean the patient from iNO after 12 hours of administration was associated with an abrupt fall in 